\title{
Canada's new Healthy Eating Strategy: Implications for health care professionals and a call to action
}

\author{
Simon L. Bacon, PhD, FTOS, FCCS, FABMR; Norm R. C. Campbell, MD, FRCP(C); Kim D. Raine, PhD, RD, FCAHS; \\ Ross T. Tsuyuki, BSc(Pharm), PharmD, MSc, FCSHP, FACC, FCAHS; Nadia A. Khan, MD, MSc, FRCP(C); \\ Manuel Arango, MA, MHA; Janusz Kaczorowski, MA, PhD
}

\section{Summary}

Nearly two-thirds of all deaths worldwide are from noncommunicable chronic diseases, with a similar proportion in Canada. According to the Global Burden of Disease Study, unhealthy eating is the leading risk for death and the second leading risk for disability in Canada. It is clear that to adequately address this major health issue, we need a comprehensive approach that includes strong governmental policy. In 2016, the Canadian government released its Healthy Eating Strategy, for which updating Canada's Food Guide was a key element. The government released the first wave of documents (including the new food guide and dietary guidelines) in January 2019, with the healthy eating patterns guidance to follow later in 2019. Much of this work aligns with a number of policies that have been developed and adopted by the Canadian health and scientific organizations that are members of the Canadian Hypertension Advisory Committee. As such, the current editorial is a call to action for the health care and scientific community, both individuals and organizations, to ensure they have policies consistent with and supportive of those that have been developed through the Hypertension Advisory Committee collaboration and to actively

To ensure that this call for action (or elements of it) has as wide an impact as possible, it is being simultaneously published in the following journals and newsletters: Canadian Pharmacists Journal, Canadian Journal of Diabetes, Canadian Journal of General Internal Medicine, Health and Fitness Journal of Canada and CV Edge. It will also be published in an upcoming issue of Canadian Family Physician. participate in providing input and feedback on the Healthy Eating Strategy through the Health Canada Stakeholder Registry.

\section{The impact of unhealthy diets on Canadians}

The World Health Organization (WHO) estimates that $63 \%$ of deaths worldwide result from noncommunicable chronic diseases (NCDs) (e.g., cardiovascular disease, cancer, diabetes and obesity). ${ }^{1-3}$ It is estimated that NCDs cost Canada $\$ 190$ billion/ year, ${ }^{4}$ a financial burden that continues to grow as NCD morbidity, comorbidity and mortality are increasing. ${ }^{5}$ Superimposed on these changes has been an escalation in the absolute numbers of people with hypertension, ${ }^{6,7}$ dyslipidemia ${ }^{8}$ and diabetes, ${ }^{9}$ all of which also significantly contribute to mortality and morbidity. ${ }^{7,8,10}$

Unhealthy eating is the leading risk for death and the second leading risk for disability in Canada. According to the Global Burden of Disease Study, dietary risks are estimated to have killed approximately 48,000 Canadians and resulted in over 800,000 years of disability in $2016 .^{11}$ The economic burden of unhealthy eating in Canada is high, accounting for an estimated $\$ 13.8$ billion/year. ${ }^{12}$ Key drivers of this unhealthy eating pattern in Canadians are increased consumption of processed foods high in calories, salt, sugar and saturated fat and a lack of whole grains, nuts, seeds, legumes, fruits and vegetables. ${ }^{13,14}$ For example, $75 \%$ of Canadians surpass the recommended dietary salt intake, and over half of Canadians are consuming diets above the recommended sugar and saturated fat levels. ${ }^{13}$

\section{The role of policy in diet}

Historically, limited access to food has been the major challenge facing humans. ${ }^{15,16}$ However, the Second Agricultural Revolution around the 18th century was seen as a major shift 


\section{Box 1 Useful websites}

Health Canada's healthy eating strategy:

https://www.canada.ca/en/services/health/campaigns/ vision-healthy-canada/healthy-eating.html

\section{Canada's Food Guide:}

https://food-guide.canada.ca/en/

Canada's Dietary Guidelines:

https://food-guide.canada.ca/en/guidelines/

\section{Canada's food guide stakeholder toolkit:}

https://www.canada.ca/en/health-canada/services/can ada-food-guide/resources/stakeholder-toolkit.html

Calgary Statement Petition:

https://www.change.org/p/enact-food-policies-to-curbchronic-disease-and-health-inequity-for-all-canadians

Health Canada Stakeholder Registry:

https://www.canada.ca/en/health-canada/corporate/ about-health-canada/public-engagement/stakeholder-registry.html

Revision process for Canada's Food Guide:

https://www.canada.ca/en/health-canada/services/can ada-food-guides/revision-process.html

Meetings and correspondence on the healthy eating strategy: https://www.canada.ca/en/services/health/campaigns/ vision-healthy-canada/healthy-eating/meetingscorrespondence.html)

in food production, leading to the Industrial Revolution and a rapid expansion in food availability. ${ }^{17}$ Since that time, there has been a concerted effort by governments to develop policies to increase the production and distribution of low-cost and more durable food that is free from infectious pathogens and detrimental toxins, with a specific emphasis on food security and economics. ${ }^{18}$ Examples of government policies include varied subsidy programs, healthy eating advertising campaigns, assessment of food for bacteria or toxins, food labelling and nutritional assistance to low-income citizens. ${ }^{19}$

It is clear that individual dietary eating patterns are influenced by a series of complex elements. ${ }^{20}$ However, to date, most Canadian government policies around the impacts of diet on NCDs have generally been based on education and target personal choice. ${ }^{18}$ Unfortunately, many factors at the sociocultural, community environment and corporate commercial level work together to directly affect an individual's capacity to purchase, prepare and consume foods. ${ }^{21-24}$ All of these factors can be strongly influenced by government policy and/or regulation. For example, Mozaffarian et al. ${ }^{18}$ highlighted ways in which governments can positively shape the dietary patterns of their citizens. These are wide-ranging strategies that are based on current behavioural and policy science and a growing evidence base for their effectiveness. Taken together, it is clear that government policy is a key driver for significantly affecting the major role diet plays in the health of Canadians. ${ }^{25}$ Furthermore, many Canadian health and scientific organizations have already supported a broad range of policy statements supporting healthy public food policy. ${ }^{26,27}$

\section{Canada's new Healthy Eating Strategy}

In October 2016, the Government of Canada, through Health Canada, released its new Healthy Eating Strategy, ${ }^{28}$ the vision for which is "Make the healthier choice the easier choice for all Canadians." As highlighted above, a number of synergistic policy strategies can be leveraged to improve the diet of Canadians and "no single intervention can tackle the complexities of the current food system." 18,25 As such, it is unsurprising that a number of internationally recommended food policies have been included in the Healthy Eating Strategy. Specifically, the strategy targets providing better nutrition information, a focus on eating behaviour, improved food quality, protecting vulnerable populations and improving food access and availability. The cornerstone initiatives of this strategy are the following:

- Revision of Canada's Food Guide

- Improved food label information and front-of-package labelling

- Reducing sodium in food

- Eliminating industrial trans fats

- Running a campaign to reduce sugary drink consumption

- Restricting marketing of unhealthy foods and beverages to children

- Expanding and updating Nutrition North Canada

Of these initiatives, the revision and reconceptualization of the Food Guide is a critical element, providing the evidencebased context for eating patterns and behaviours of Canadians and having the greatest impact on the day-to-day activities of health care professionals.

\section{Canada's new Food Guide}

Today we have unprecedented access to information. The majority of Canadians obtain various health care and related information from the Internet. ${ }^{29}$ This phenomenon, coupled with the surge in usage of social media, ${ }^{30}$ has created a nutrition information environment that is strewn with contradictory messages and potentially erroneous, misleading or harmful advice. ${ }^{31,32}$ In this context, it is unsurprising that the majority of people felt that the Canadian Food Guide, which was originally developed in 1992 and updated in 2007, needed to be updated not only for content but also for usability. ${ }^{33}$

To achieve its goal of developing a new approach to food and nutrition, ${ }^{34}$ the Canadian government has a multiphase approach planned: assessing current evidence to update dietary guidance policy, provision of simplified resources (including visuals, tips and messages) and launching an integrated, 
mobile-first online solution. The government has proposed that the Dietary Guidance Policy be further broken down with staged releases of the new Food Guide ${ }^{35}$ and Canada's Dietary Guidelines $^{36}$ (which were released in January 2019) and health eating patterns (planned release later in 2019).

The 2019 Food Guide ${ }^{35}$ has been built around 3 of the 4 guiding principles of the Dietary Guidelines, ${ }^{36}$ rather than being a predominantly prescriptive food guide like the previous version. The key elements that have informed the new Food Guide are as follows: 1) "foundation for healthy eating" (i.e., evidence-based foods that improve health), ${ }^{37}$ 2) "foods and beverages that undermine healthy eating" (i.e., evidence-based foods that are detrimental to health) ${ }^{37}$ and 3) "importance of food skills" (i.e., the skills and knowledge that are needed to be able to implement points 1 and 2, as well as allowing people to navigate the complex food environment that we live in). An example of how a dietary guideline translates to the food guide and then to policy would be the following: processed foods and beverages are likely to contribute to excess sodium, free sugars or saturated fat consumption, which undermine healthy eating. ${ }^{36}$ This then translates into a recommendation in the food guide to "limit highly processed foods " and to "replace sugary drinks with water," ${ }^{35}$ which, in theory, should tie to federal, provincial or local policy changes around the use of trans fats in industrially produced foods, taxation of sugary drinks or purchasing practices ${ }^{38}$ (aspects that align with the fourth element of the Dietary Guidelines: implementation).

It is envisaged that these guiding principles will also be the pillars for the development of Canada's Healthy Eating Pattern for Health Professionals and Policy Makers, which will be part of the next release. Given the diversity of the Canadian population, it is clear that a static document that provides rudimentary guidelines on food groups is probably going to be inadequate to service the majority of Canadians. As such, the proposed Canada's Healthy Eating Pattern suite of tools will provide information on potential eating plans (i.e., more specific guidance on the amounts and types of food based on contextual considerations of an individual, such as sociodemographic data). It is anticipated that these will also incorporate up-to-date statistical data from ongoing food surveillance surveys (e.g., Canadian Community Health Survey) and evolving nutritional science data (e.g., systematic reviews of macro- and micronutrient food intake and NCD risk). If achieved, these "healthy eating patterns/plans" will provide tailored information that is up to date and context specific to any Canadian.

To ensure that the core tenets of the new Food Guide reach as many people as possible, the fourth guiding principle of the Dietary Guidelines ${ }^{36}$ focuses on implementation. Health Canada has indicated it is also developing a series of tools that will hopefully improve the effectiveness of the guide. A series of visual aids around key messaging and actionable tips, including simplified information and promoting food skills, have already been developed, ${ }^{39}$ with dissemination through various media such as videos and social media already under way. However, the critical driver of these efforts will be the development of an interactive web-based application. It is anticipated that this mobile interface, which is due for release later in 2019, will provide customized usable information that will enhance the Food Guide experience for both the general population and health care professionals.

\section{The role of health care professionals in the new Healthy Eating Strategy and Food Guide}

Moving forward, there are 3 key areas where health care professionals will be critical for the success of the Healthy Eating Strategy and Food Guide: consultation, implementation and holding government to account. ${ }^{37}$

\section{Consultation}

Transparency in the food guideline development is a driving tenet in the new strategy. One criticism of previous food guides was that too many vested interests were represented (e.g., the food industry). ${ }^{40,41}$ The hallmarks of the current process include extensive consultation with health care professional, academic, patient, community and health care groups (with all meetings and correspondence on healthy eating being published on a website ${ }^{42}$ ) (Figure 1). Industry has not participated in the process. Moving forward, it is expected that this will continue. It is intended that there will be continual consultation with key academic and clinical experts on the content of the Dietary Guidance Policy, as well as user-driven changes made to the web-based application and tools to enhance accessibility and usability.

Health Canada has facilitated this process by setting up a Stakeholder Registry ${ }^{43}$ where anyone can sign up to participate in the consultation process. As clinicians and academics, we have an opportunity to ensure that all aspects of the Healthy Eating Strategy stay current, meaningful and accessible.

\section{Implementation}

Ultimately, the success of the Healthy Eating Strategy will be measured by the way it has affected the dietary habits of Canadians and thus made meaningful improvements in the long-term health of the nation. Although the government will undoubtedly undertake a variety of campaigns to raise awareness of the various elements and tools of the Healthy Eating Strategy and Food Guide, health care professionals will play a significant role in implementing these at the individual level and through our organizations at a population level.

It is hoped that the tools that will be developed, especially around the Food Guide, ${ }^{39}$ will be pertinent for both patients and health care professionals. Furthermore, making health care professionals aware of these tools and how best to optimally implement them will be important. Identifying the key drivers of why and how health care professionals would want to incorporate these into their practice will be critical in empowering 


\section{FIGURE 1 Federal and stakeholder roles in the Healthy Eating Strategy}

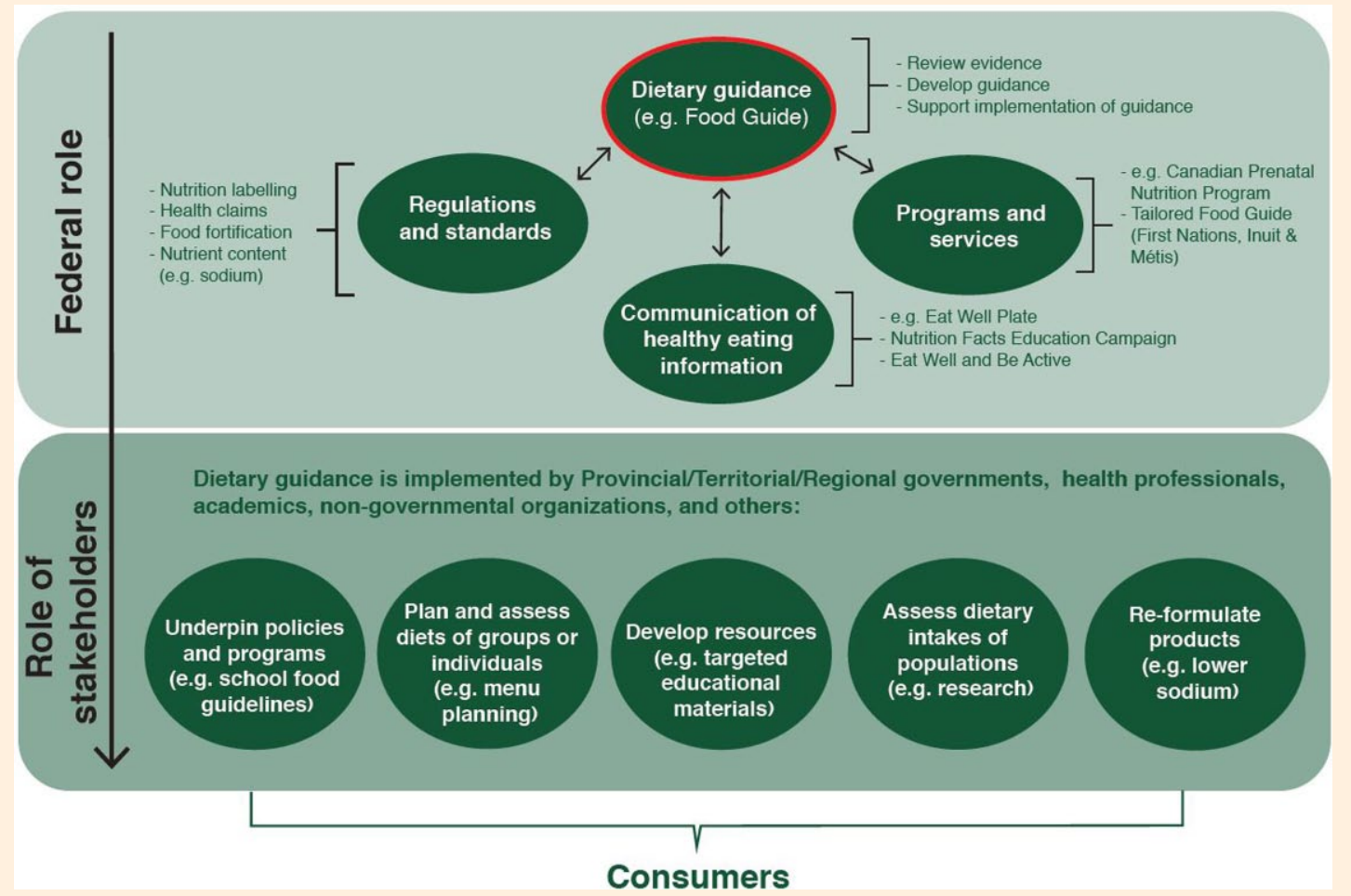

Produced with permission from Health Canada. ${ }^{37}$

patients in their behaviour change efforts. Examples of where health care practitioners can work to enhance implementation include using the personalization feature for the Food Guide to better tailor meals for patients with complex NCDs, developing local healthy food procurement policies, ${ }^{38}$ enhancing the education of health care providers through reforming preand postcertification curriculum and working to incorporate dietary quality and food security assessment into standard electronic health records. Developing local, provincial and national quality measures of implementation can provide an appropriate framework to engage the community and track success. ${ }^{44}$

\section{Accountability}

As intimated above, the first step of accountability is to be able to systematically monitor any implemented changes so that they can be evaluated for progress and potential readjustment. This means that systems need to be developed that can be leveraged to hold the federal government accountable. Individuals, as well as health institutions, societies and associations, need to ensure that the Healthy Eating Strategy is actually translated into meaningful action by the federal government.

Given the decentralized health care structure in Canada, pushing to provide a coherent and interconnected extension to the Healthy Eating Strategy across all levels of governance (i.e., the local health care environment, city and borough levels and provincially), as well as a system for monitoring its implementation, is also important. Having a coordinated strategy across different ministries and governmental bodies would provide the optimal scenario to affect the health of Canadians.

One final aspect of accountability that needs to be addressed is that of conflicts of interest. There is clear evidence in the United States that industry, through its lobbyists, can have undue influence on policy. ${ }^{45,46}$ While Health Canada has done an unprecedented job of developing the Healthy Eating Strategy independently from industry, we all must be cognizant of our own biases and conflicts. This is especially true as we work to develop more comprehensive implementation and surveillance plans.

\section{Conclusion}

There is clear evidence that dietary factors are the greatest modifiable risk factor for NCDs. Past successes in tackling national behavioural issues (e.g., tobacco use) have relied on a multipronged approach, meaning that we as health care professionals need to be actively involved in all aspects to ensure that there is a major culture change around diet and eating behaviours, leading to a subsequent improvement in health. Historically, Canada's Food Guide has provided a more limited role than one would hope in affecting the dietary patterns of Canadians. Through the Healthy Eating Strategy, Health Canada has developed a platform that has the potential to lay the foundation for meaningful change in improving the eating behaviours of Canadians. The new Food Guide has been developed through 
extensive consultation, a process that is expected to continue to ensure its relevancy and has been structured to provide flexibility for the majority of Canadians. However, it is important to remember that it is difficult for many Canadians to eat healthily in their current food environment. As highlighted in the recent Calgary Statement on policies for nutrition and health ${ }^{47}$ (see Appendix 1, available online at www.cpjournal.ca), "There is a need to create food environments through public policies that support Canadians in maintaining healthy diets where they live, learn, work and play." As such, the Healthy Eating Strategy can be seen as a starting point for the continued development of policies that emphasize the best interests of Canadians, rather than those of industry or certain agricultural sectors.

Canadian health care professionals and academics have a key role to play in the implementation of the policies and tools from the Healthy Eating Strategy (e.g., the Food Guide), ensuring accountability at all levels and the evolution of the philosophies that underpin the Healthy Eating Strategy through the continual development of appropriate policies. If we are able to meaningfully improve the Canadian diet, we will be able to reap significant health, economic and societal benefits. In 2011, Canadian health care and scientific organizations developed a Framework for the prevention and control of hypertension. ${ }^{26,27}$ Given that $80 \%$ of hypertension is associated with unhealthy diets, the Framework highlighted the central role of unhealthy diets and emphasized the need to create healthy eating environments through health food policies. It is notable that Canadian health care and scientific organizations give the highest priority to efforts to implement healthy food policies in the Framework. ${ }^{26}$ Furthermore, since the development of the Framework, Canadian health and scientific organizations of the Canadian Hypertension Advisory Committee have created consensus policy statements on restrictions of marketing unhealthy food to children; healthy food procurement; increasing research, monitoring and evaluation of Canada's food supply and food policies; defining healthy foods; taxation of unhealthy food and subsidies for healthy food; and reducing financial conflicts of interest with the food sector. They have also created fact sheets and calls to action on dietary sodium and unhealthy eating. ${ }^{48,49}$ All of these would seem to align with the main tenets of the Healthy Eating Strategy and provide a pathway to translate policy to action.

\section{Call to Action}

We call on the whole Canadian health care and scientific community, both individuals and organizations, to ensure they have policies consistent with and supportive of those in the Calgary Statement ${ }^{47}$ and the Call for Action to Implement a Healthy Food Policy Agenda, ${ }^{25}$ including all the related policy statements, ${ }^{48,49}$ and advocate to all levels of government to rapidly implement such policies. For example, Canadian health care and scientific organizations can actively encourage their membership to consider signing the Calgary Statement Petition ${ }^{47}$ and join other healthy food policy advocacy efforts. Furthermore, we encourage the community to actively participate in providing input and feedback on the Healthy Eating Strategy through the Health Canada Stakeholder Registry. ${ }^{43}$ This could be the most important thing we do for our patients and our society.

\section{Organizations involved in and journals that are publishing this call}

This editorial was generated from members of the Canadian Hypertension Advisory Committee, which is a coalition of Canadian health and scientific organizations (see Appendix 2 for specific organizations that have contributed to statements from the committee) and was reviewed by all participating member organizations. The authors of this editorial represent the following organizations that participate in the Canadian Hypertension Advisory Committee: Canadian Association of Cardiovascular Prevention and Rehabilitation, Hypertension Canada, Canadian Pharmacists Association and the Heart and Stroke Foundation of Canada-these organizations have not directly endorsed this specific editorial.

From the Montreal Behavioural Medicine Centre (Bacon), CIUSSS-NIM, Hôpital du Sacré-Coeur de Montréal; the Department of Health, Kinesiology and Applied Physiology (Bacon), Concordia University, Montreal, Quebec; the Department of Medicine, Physiology and Pharmacology and Community Health Sciences (Campbell), O'Brien Institute for Public Health and Libin Cardiovascular Institute of Alberta, University of Calgary, Calgary; the School of Public Health (Raine), University of Alberta, Edmonton; the Department of Medicine (Tsuyuki), Division of Cardiology, University of Alberta, Edmonton, Alberta; the Department of Medicine (Khan), Division of General Internal Medicine, University of British Columbia, Vancouver, British Columbia; The Heart and Stroke Foundation of Canada (Arango), Ottawa, Ontario; the Department of Family and Emergency Medicine (Kaczorowski), University of Montreal; and the Centre de Recherche CHUM (Kaczorowski), Montreal, Quebec. Contact Simon.bacon@concordia.ca.

Declaration of Conflicting Interests: Dr. Bacon reports grants from GSK and Abbvie and personal fees from Schering-Plough, Merck, Astra-Zenica, Sygesa, Novartis, Jansen and Bayer outside the submitted work. Dr. Campbell reports personal fees and other from Novartis Foundation and Midway Corp outside the submitted work and being an unpaid member of World Action on Salt and Health and an unpaid consultant on dietary sodium to numerous governmental and nongovernmental organizations. Dr. Raine has nothing to disclose. Dr. Tsuyuki reports grants from Merck Canada, Sanofi Canada and AstraZencia and personal fees from Merck Canada outside the submitted work. Dr. Khan has nothing to disclose. Mr. Arango has nothing to disclose. Dr. Kaczorowski has nothing to disclose. 


\section{References}

1. World Health Organization. Preventing chronic diseases: a vital investment: a WHO Global Report. Geneva (Switzerland): World Health Organization; 2005. 2. Flegal KM, Kruszon-Moran D, Carroll MD, et al. Trends in obesity among adults in the United States, 2005 to 2014. JAMA 2016;315:2284-91.

3. Fryar CD, Carroll MD, Ogden CL. Prevalence of overweight, obesity and extreme obesity among adults: United States, trends 1960-1962 through 20092010. Washington (DC): Centers for Disease Control and Prevention; 2015.

4. Chronic Disease Prevention Alliance of Canada. Submission to SOCI regarding Bill S-228, An Act to amend the Food and Drugs Act (prohibiting food and beverage marketing directed at children). June 13, 2017. Available: https://sen canada.ca/content/sen/committee/421/SOCI/Briefs/ChronicDiseasePreventi onAlliance_e.pdf (accessed Jan. 15, 2019).

5. World Health Organization. Global status report on non-communicable diseases, 2010. 2011. Available: www.who.int/nmh/publications/ncd_report2010/ en/ (accessed Jan. 15, 2019).

6. Schiffrin EL, Campbell NRC, Feldman RD, et al. Hypertension in Canada: past, present and future. Ann Glob Health 2016;82:288-99.

7. Padwal RS, Bienek A, McAlister FA, Campbell NRC. Epidemiology of hypertension in Canada: an update. Can J Cardiol 2016;32:687-94.

8. Asghari S, Aref-Eshghi E, Hurley O, et al. Does the prevalence of dyslipidemias differ between Newfoundland and the rest of Canada? Findings from the electronic medical records of the Canadian Primary Care Sentinel Surveillance Network. Frontiers Cardiovasc Med 2015;2:1.

9. Cheng AYY. Introduction. Can J Diabetes 2013;37:S1-S3.

10. Vasan RS, Sullivan LM, Wilson PWF, et al. Relative importance of borderline and elevated levels of coronary heart disease risk factors. Ann Int Med 2005;142:393-402.

11. Institute for Health Metrics and Evaluation. Global burden of disease arrow diagram. 2016. Available: http://vizhub.healthdata.org/gbd-compare/ (accessed May 3, 2018).

12. Lieffers JRL, Ekwaru JP, Ohinmaa A, Veugelers PJ. The economic burden of not meeting food recommendations in Canada: the cost of doing nothing. PLoS ONE 2018;13:e0196333.

13. Garriguet D. Sodium consumption at all ages. Health Rep 2007;18:47-52.

14. Langlois K, Garriguet D. Sugar consumption among Canadians of all ages. Health Rep 2011;22:23-7.

15. Jones PM. Agricultural enlightenment: knowledge, technology and nature, 1750-1840. Oxford (UK): Oxford University Press; 2016.

16. Mokyr J. The enlightened economy: an economic history of Britain 17001850. New Haven (CT): Yale University Press; 2012.

17. Kessler DA. The evolution of national nutrition policy. Annu Rev Nutr 1995; 15:xiii-xxvi.

18. Mozaffarian D, Angell SY, Lang T, Rivera JA. Role of government policy in nutrition-barriers to and opportunities for healthier eating. $B M J$ 2018;361:k2426.

19. Wilde P. Food policy in the United States: an introduction. New York (NY): Routledge; 2013.

20. Afshin A, Micha R, Khatibzadeh S, et al. Dietary policies to reduce noncommunicable diseases. In: Brown GW, Yamey G, Wamala S, eds. The handbook of global health policy. Chichester (UK): Wiley-Blackwell; 2014:177-94.

21. Brug J. Determinants of healthy eating: motivation, abilities and environmental opportunities. Family Practice 2008;25:150-i55.

22. Brug J, Kremers SP, Lenthe FV, et al. Environmental determinants of healthy eating: in need of theory and evidence: symposium on 'Behavioural nutrition and energy balance in the young. Proc Nutr Soc 2008;67:307-16.
23. Mozaffarian D. Salt, sugar and fat or branding, marketing and promotion? Lancet 2013;382:1322-3.

24. Mason P, Lang T. Sustainable diets. London (UK): Routledge; 2017.

25. Canadian Hypertension Advisory Committee. Eat healthy, stay healthy. A call for action to implement a healthy food policy agenda. Consensus Statement of Canadian Health and Scientific Organizations. 2016. Available: www .hypertensiontalk.com/wp-content/uploads/2014/02/Final-Call-for-healthyFood_EN_with-supporters_April-1-2016.pdf (accessed Feb. 11, 2019).

26. Campbell N, Young ER, Drouin D, et al. A framework for discussion on how to improve prevention, management and control of hypertension in Canada. Can J Cardiol 2012;28:262-9.

27. Healthy Blood Pressure Framework Steering and Drafting Committee. Pan Canadian framework on the prevention and control of hypertension: a discussion paper on the way forward. 2012. Available: https://hypertension.ca/wpcontent/uploads/2017/11/2012_Final_Hypertension_Framework_English .pdf (accessed Oct. 30, 2018).

28. Government of Canada. Health Canada's healthy eating strategy. 2018. Available: https://www.canada.ca/en/services/health/campaigns/vision-heal thy-canada/healthy-eating.html (accessed Oct. 30, 2018).

29. Underhill C, McKeown L. Getting a second opinion: health information and the Internet. Health Rep 2008;19:65-9.

30. Smith A, Anderson M. Social media use in 2018: Pew Research Center 2018. Available: www.pewinternet.org/2018/03/01/social-media-use-in-2018/ (accessed Oct. 30, 2018).

31. Nagler RH. Adverse outcomes associated with media exposure to contradictory nutrition messages. J Health Comm 2014;19:24-40.

32. Fox S, Duggan M. Health Online 2013: Pew Research Center 2013. Available: www.pewinternet.org/2013/01/15/health-online-2013/ (accessed Oct. 30, 2018).

33. Ipsos Public Affairs. Canada's Food Guide Consultation-Phase 1: What We Heard Report. Ottawa (ON): Ipsos; 2016.

34. Government of Canada. Revision process for Canada's Food Guide. 2018. Available: https://www.canada.ca/en/health-canada/services/canada-foodguides/revision-process.html (accessed Oct. 30, 2018).

35. Government of Canada. Canada's Food Guide. 2019. Available: https:// food-guide.canada.ca/en/ (accessed Jan. 29, 2019).

36. Government of Canada. Canada's Dietary Guidelines. 2019. Available: https://food-guide.canada.ca/en/guidelines/ (accessed Jan. 29, 2019).

37. Health Canada. Evidence review for dietary guidance: summary of results and implications for Canada's Food Guide 2015. Ottawa (ON): Health Canada; 2016.

38. Campbell N, Duhaney T, Arango M, et al. Healthy food procurement policy: an important intervention to aid the reduction in chronic noncommunicable diseases. Can J Cardiol 2014;30:1456-9.

39. Government of Canada. Canada's food guide stakeholder toolkit. 2019. Available: https://www.canada.ca/en/health-canada/services/canada-food-gui de/resources/stakeholder-toolkit.html (accessed Jan. 29, 2019).

40. Kondro W. Proposed Canada Food Guide called "obesogenic." CMAJ 2006;174:605.

41. Vogel L. Meat and dairy supporters seek industry-friendly changes to food guide. CMAJ 2018;190:E201.

42. Government of Canada. Meetings and correspondence on healthy eating. 2016. Available: https://www.canada.ca/en/services/health/campaigns/visionhealthy-canada/healthy-eating/meetings-correspondence.html (accessed Jan. 29, 2019). 
43. Government of Canada. Stakeholder Registry (CSIMS): sign up for health consultations. 2017. Available: https://www.canada.ca/en/health-canada/corp orate/about-health-canada/public-engagement/stakeholder-registry.html (accessed Jan. 29, 2019).

44. Ingram R, Scutchfield FD, Costich JF. Public health departments and accountable care organizations: finding common ground in population health. Am J Pub Health 2015;105:840-6.

45. Brownell K, Battle Horgen K. Food fight: the inside story of the food industry, America's obesity crisis and what we can do about it. New York (NY): McGrawHill; 2003.
46. Shipan CR, Volden C. Bottom-up federalism: the diffusion of antismoking policies from US cities to states. Am J Pol Sci 2006;50:825-43.

47. The Calgary Statement. Enact food policies to curb chronic disease and health inequity. 2018. Available: https://www.change.org/p/enact-food-polic ies-to-curb-chronic-disease-and-health-inequity-for-all-canadians (accessed Oct. 30, 2018).

48. Hypertension Canada. Advocacy (English page). Available: https://hyper tension.ca/advocacy/ (accessed Dec. 7, 2018).

49. Hypertension Canada. Mobilisation (page en francais). Available: https:// hypertension.ca/fr/advocacy/ (accessed Dec. 7, 2018). 